\title{
Progress in Diagnosis and Endoscopic Treatment of Stanford B Penetrating Aortic Ulcers
}

\author{
Lei-lei Yan, Qingran Liu, Chengde Zhang* \\ Shandong Province, China \\ *Corresponding author: Chengde Zhang, xgwkzcd@sina.com
}

Department of Interventional Vascular Surgery, Binzhou People's Hospital, No.515 Huanghe 7 Road, Binzhou 256610,

\begin{abstract}
Penetrating aortic ulcers is rare in clinical practice, and it is necessary to intervene in this type of aortic perforating ulcer because it can be accompanied by major arterial dissection and intermural hematoma. With the widespread application and technical advancement of follow-up thoracic aortic endovascular repair (TEVAR), endovascular treatment has become the first choice for symptomatic aortic perforating ulcers. In this review, we will review the diagnosis, diagnosis and endovascular treatment of aortic perforating ulcer.
\end{abstract}

Keywords: Stanford type B penetrating aortic ulcers; Intrathoracic aortic repair; Indications for endovascular treatment

Publication date: July 2021; Online publication: July 31, 2021

\section{Introduction}

Penetrating aortic ulcers (PAU)is a rare but life-threatening disease ${ }^{[1-5]}$. It is commonly known as aortic syndrome ${ }^{[6]}$, along with aortic dissection and intermural hematoma ${ }^{[1]}$, of which penetrating ulcer is the least fatal ${ }^{[1]}$. PAU was first defined 80 years ago as a ruptured atherosclerotic plaque in the aortic wall that penetrates the intima or the inner elastic plate, penetrates the media, and exhumes with ulcerative changes, mostly located under the adventitia, with or without intramural hematoma formation ${ }^{[1,3,7]}$.

PAU has similar clinical characteristics with intramural hematoma (IMH) and aortic dissection (AD), and the three can coexist and transform each other. PAU formed with hematoma and was confined to the middle layer to form $\mathrm{IMH}$, and ruptured inward to progress to AD. However, many questions remain regarding the pathophysiology and treatment modalities, especially for asymptomatic PAU patients. Most PAU are usually asymptomatic and do not require urgent invasive treatment, but for those with clinical symptoms, intervention is required. Previously, surgical treatment was considered an option for symptomatic and ruptured PAU ${ }^{[8]}$. With the development of endovascular technology and its wide application, endovascular stent implantation has gradually become the first choice for these patients. However, the indications for treatment of asymptomatic patients remain controversial ${ }^{[9]}$.

\section{Treatment indications}

Stanford Type B PAU is often clinically classified into two types: complex and non-complex. Complexity refers to aortic rupture, hypotension, shock, recurrent or refractory pain, intractable hypertension, and malperfusion of vital organs. Recurrent or refractory pain is an important indicator of surgery. Ganaha ${ }^{[4]}$ believed that the combination of pleural effusion with gradual increase and the maximum diameter and maximum depth of PAU were important factors to evaluate whether surgical intervention was needed. In their series of studies, they found that patients with PAU combined with IMH had a significantly worse prognosis compared to patients with IMH alone. Endoluminal repair therapy is recommended for patients with both PAU and IMH and a causal relationship exists between them ${ }^{[10]}$. The study of Patel et al ${ }^{[11]}$ 
confirmed that PAU combined with IMH was a risk factor for treatment failure of TEVAR. Rapid increase in aortic diameter and hemodynamic instability are important criteria for emergency surgery ${ }^{[7,12]}$. In a recent report, aortic diameter was significantly smaller in asymptomatic PAU patients than in symptomatic patients ${ }^{[13]}$, and aortic diameter $>50 \mathrm{~mm}$ was an independent risk factor for death ${ }^{[12]}$.

Clinically, AD is classified into Stanford type A and type B. Type A refers to dissection involving the ascending aorta regardless of the location of the rupture. Type B involves the aortic arch and the dissection beyond. The classification of PAU can be based on this standard [14, 15], and emergency surgery is recommended for type A PAU, while conservative treatment, endovascular repair, and surgical treatment can be selected for type B PAU according to the situation. Recent reports have confirmed that endovascular treatment is preferred for symptomatic PAU of the descending aorta that is not suitable for surgical repair. EVRA therapy for asymptomatic PAU is currently a level III recommendation ${ }^{[10]}$, for which it is critical to evaluate the appropriate timing of intervention. The study confirmed that close follow-up, including CT or MRI imaging, was necessary ${ }^{[5]}$. In addition, PET-CT has important value in assessing the degree of inflammation, which can reflect the progression of PAU ${ }^{[16]}$. For asymptomatic PAU, at least 2 close followups, including aortic CTA or MRA, should be performed in the first year after diagnosis, or once a year if the disease is stable ${ }^{[13]}$. The indication for its treatment is progressive PAU, including symptoms and morphology (such as with pleural effusion, intermural hematoma, pseudoaneurysm, increased ulcer depth, etc.), and endovascular repair is preferred in these patients ${ }^{[5,17]}$.

\section{Current situation of endovascular treatment}

For symptomatic PAU, the conventional treatment has been surgical repair and aortic replacement ${ }^{[7]}$. However, the majority of PAU patients are not suitable for conventional surgery due to general conditions and comorbidities. In several large center studies, mortality rates for descending aortic disease with conventional surgery have been found to be between $5 \%$ and $20 \%{ }^{[18-21]}$, and around $15 \%$ for descending aortic PAU ${ }^{[22,23]}$. The in-hospital mortality rate for endovascular treatment is $7 \%{ }^{[24]}$. Although surgery is an effective treatment, endovascular repair has emerged as a treatment that significantly reduces patient risk. The study found that endovascular repair for thoracic and abdominal aortic diseases, including PAU, was associated with lower mortality and complications than open surgery. For the treatment of descending aorta and abdominal aortic aneurysms, the use of open surgical repair is gradually decreasing ${ }^{[25]}$. PAU is mostly a segmental lesion limited to the vessel wall, so endovascular repair is an ideal treatment for PAU [27].

In a recent study, 65\% of PAU patients were found to have symptoms of acute aortic syndrome (AAS) ${ }^{[13]}$, and patients with clinical symptoms had significantly higher perioperative mortality than asymptomatic patients ${ }^{[17]}$. Gottardi et al ${ }^{[12]}$ found that the in-hospital mortality rate of PAU was $11 \%$. In a retrospective study of PAU, Demers et al ${ }^{[27]}$ found that $23 \%$ of PAU patients had aortic rupture, the 30-day mortality rate was $12 \%$, and the patients with clinical symptoms was $37 \%$. Brinster et al ${ }^{[28]}$ reported EVAR for descending aortic PAU in $76 \%$ of patients with clinical symptoms, and they reported a $0 \%$ in-hospital mortality rate.

\section{Postoperative complications of EVAR}

The fatal complications after EVAR in PAU patients are mainly related to cardiac complications. Currently, although EVAR has achieved good results in the perioperative period of PAU in the thoracic and abdominal aorta, the 5-year survival rate in these patients is still around $65 \%{ }^{[29]}$. At the same time, there are many precautions in the course of treatment, such as difficult approach, coronary artery disease, internal leakage and neurological complications.

Severe coronary artery disease is very common in PAU patients, and the incidence of cardiac 
complications after EVAR is higher in PAU patients ${ }^{[13]}$ with some reports reaching as high as $1 / 3{ }^{[17]}$. Therefore, a comprehensive preoperative cardiac evaluation of PAU patients is very important.

Leakage is another common complication after EVAR ${ }^{[30]}$. In PAU patients, extensive atherosclerosis is not conducive to stent anchoring. In Botta et al ${ }^{[29]}$, the incidence of leakage reached $18 \%$, and most of these patients required re-intervention. Another report found that $19 \%$ and $4 \%$ of patients had single and secondary leaks, respectively, and that $36 \%$ of these patients required additional intervention ${ }^{[17]}$. PAU is often associated with extensive systemic atherosclerosis, with increased perioperative risk in patients with this approach due to the presence of severe calcification in the femoral and iliac arteries ${ }^{[31]}$. Therefore, preoperative careful interpretation of image data to evaluate the safety of the approach is of Paramount importance. If necessary, other approaches such as retroperitoneal exposure of the iliac artery can be chosen to establish the approach.

In EVAR surgery, an adequate anchoring area is the cornerstone of successful surgery. This area must be at least $15 \mathrm{~mm}$, but this means that more aortic wall is covered by stent. Studies have confirmed that the length of aorta covered by stents is an independent risk factor for spinal cord ischemia, so large segmental artery coverage should be avoided as much as possible ${ }^{[32]}$.

\section{Conclusion}

According to the characteristics of PAU, it is very important to develop a careful and effective treatment plan. Symptomatic PAU is a rare and severe pathological condition characterized by acute aortic syndrome that can progress to aortic rupture with catastrophic consequences. Now, there is a growing recognition that symptomatic PAU can be fatal. Concomitant symptoms and ulceration diameter (greater than 20mm) and depth (greater than 10mm) were considered risk factors for rupture. For patients with combined symptoms, endoscopic treatment is preferred. For asymptomatic patients, due to the lack of reliable evidence, it is still controversial, and close follow-up is necessary. In the absence of randomized controlled trials, EVAR is an effective treatment option.

EVAR has achieved good results in the treatment of aortic perforating ulcer in a short period of time and has important clinical value. For PAU requiring surgery, endoscopic treatment should be preferred. Although approximately $40 \%$ of patients require emergency intervention, EVAR has achieved satisfactory outcomes in terms of lower in-hospital mortality, lower surgical mortality, and lower surgical failure rates. For PAU patients undergoing EVAR, overall survival is closely related to complications, so rigorous, scientific risk assessment and perioperative management are critical for these patients

\section{Funding}

The work was supported by a grant from 2019-2020 Shandong Province Traditional Chinese Medicine Science and Technology Development Plan (No.2019-0928).

\section{Disclosure statement}

The authors declare that there is no conflict of interest that would prejudice the impartiality of this scientific work.

\section{References}

[1] Stanson AW, Kazmier FJ, Hollier LH, et al., 1986, Penetrating Atherosclerotic Ulcers of the Thoracic Aorta: Natural History and Clinicopathologic Correlations. Ann. Vasc. Surg. 1: 15-23.

[2] Harris JA, Bis KG, Glover JL, et al., 1994, Penetrating Atherosclerotic Ulcers of the Aorta. J. Vasc. 
Surg. 19: 90-8.

[3] Shennan T, 1934, Dissecting Aneurysms. Medical Research Council, Special Report Series No. 193, HSMO, London.

[4] Ganaha F, Miller DC, Sugimoto K, et al., 2002, Prognosis of Aortic Intramural Hematoma With and Without Penetrating Atherosclerotic Ulcer: A Clinical and Radiological Analysis. Circulation, 106: 342-8. 762 Georgiadis et al. (C) 2013 The Authors ANZ Journal of Surgery (C) 2013 Royal Australasian College of Surgeons.

[5] Hyhlik-Dürr A, Geisbüsch P, Kotelis D, Böckler D, 2010, Endovascular Repair of Infrarenal Penetrating Aortic Ulcers: A Single-Center Experience in 20 Patients. J. Endovasc. Ther. 17: 5104.

[6] Nienaber CA, Ince H, Petzsch M et al., 2002, Endovascular Treatment of Thoracic Aortic Dissection and its Variants. Acta Chir. Belg. 102: 292-8.

[7] Coady MA, Rizzo JA, Hammond GL, et al., 1998, Penetrating Ulcer of the Thoracic Aorta: What is it? How do We Recognize it? How do We Manage it? J Vasc Surg, 27:1006e16. 6.

[8] Roldan CJ, 2011, Penetrating Atherosclerotic Ulcers of the Thoracic Aorta: Do Emergency Physicians Need to Worry?, J Emerg Med Epub ahead of print.

[9] Sundt TM, 2007, Intramural Hematoma and Penetrating Atherosclerotic Ulcers of the Aorta. Ann Thorac Surg, 83:S835-S841; discussion S846-S85.

[10] Svensson LG, Kouchoukos NT, Miller DC, et al., 2008, Expert Consensus Document on the treatment of Descending Thoracic Aortic Disease using Endovascularstent-Grafts. Ann Thorac Surg, $85: \mathrm{S} 1-\mathrm{S} 41$,

[11] Patel HJ, Williams DM, Dasika NL, et al., 2010, The Challenge of Associated Intramural Hematomawith Endovascular Repair for Penetrating Ulcers of the Descending Thoracic Aorta. J Vasc Surg, 51:829-835.

[12] Gottardi R, Zimpfer D, Funovics M, et al., 2008, Mid-Term Results after Endovascularstent-Graft Placement due to Penetrating Atherosclerotic Ulcers of the Aorta. EurJ Cardiothorac Surg, 33:10191024.

[13] Bischoff MS, Geisbüsch P, Peters AS, et al., 2011, Ulcers of the Aorta. 36(6), 498-504. doi:10.1007/s00059-011-3513-9.

[14] Kodolitsch Y von, Nienaber CA, 1998, Ulcer of the Thoracic Aorta: Diagnosis, Therapy and Prognosis. Z Kardiol 87:917-927

[15] Stamou SC, Kouchoukos NT, 2011, Penetrating Atherosclerotic Ulcers of the Aorta. J Am Coll Cardiol, 57:1327.

[16] Kuehl H, Eggebrecht H, Boes T, et al., 2008, Detection of Inflammation in Patients with Acute Aortic Syndrome: Comparison of FDG-PET/CT Imaging and Serological Markers of Inflammation. Heart, 94:1472-1477.

[17] Geisbusch P, Kotelis D, Weber TF, et al., 2008, Early and Midterm Results after Endovascularstent Graft Repair of Penetrating Atherosclerotic Ulcers of the Aorta. J Vasc Surg, 48:1361-13.

[18] Coselli JS, Conklin LD, LeMaire SA, 2002, Thoracoabdominal Aortic Aneurysm Repair: Review and Update of Current Strategies. Ann Thorac Surg, 74:S1881-S1884; discussion S1892-S1888.

[19] Estrera AL, Rubenstein FS, Miller CC 3rd, et al., 2001, Descending Thoracic Aortic Aneurysm: Surgical Approach and Treatment Using the Adjuncts Cerebrospinal Fluid Drainage and Distal Aortic Perfusion. Ann Thorac Surg, 72:481- 486.

[20] Estrera AL, Miller CC 3rd, Chen EP et al., 2005, Descending Thoracic Aortic Aneurysm Repair: 12-Year Experience Using Distal Aortic Perfusion and Cerebrospinal Fluid Drainage. Ann Thorac Surg, 80:1290- 1296; discussion 1296. 
[21] Wong DR, Parenti JL, Green SY, et al., 2011, Open Repair of Thoracoabdominal Aortic Aneurysm in the Modern Surgical Era: Contemporary Outcomes in 509 Patients. J Am Coll Surg, 212:569579; discussion 579-581.

[22] Cho KR, Stanson AW, Potter DD, et al., 2004, Penetrating Atherosclerotic Ulcers in the Descending Thoracic Aorta and Arch. J Thorac Cardiovasc Surg, 127:1393-1399; discussion 1399-1401 9. Coady MA, Rizzo JA, Ha.

[23] Tittle SL, Lynch RJ, Cole PE, et al., 2002, Midterm Follow-Up of Penetrating Ulcer and Intramural Hematoma of the Aorta. J Thorac Cardiovasc Surg, 123:1051-1059.

[24] Eggebrecht H, Plicht B, Kahlert P, Erbel R, 2009, Intramural Hematoma and Penetrating Ulcers: Indicationsto Endovascular Treatment. Eur J Vasc Endovasc Surg, 38:659-665.

[25] Giles KA, Pomposelli F, Hamdan A, et al., 2009, Decrease in Total Aneurysm-Related Deathsin the Era of Endovascular Aneurysm Repair. J Vasc Surg, 49:543-550; discussion 550-541.

[26] Lansman SL, Saunders PC, Malekan R, Spielvogel D, 2010, Acute Aortic Syndrome. J Thorac Cardiovasc Surg, 140:S92-S97; discussion S142-S146.

[27] Demers P, Miller DC, Mitchell RS, et al., 2004, Stent-Graft Repair of Penetrating Atherosclerotic Ulcers in the Descending Thoracic Aorta: Early and Mid-Term Results. Ann Thorac Surg, 77:8186.

[28] Brinster DR, Wheatley GH 3rd, Williams J, et al., 2006, Are penetrating aortic ulcers best treated using an endovascular approach? Ann Thorac Surg, 82:1688-1691.

[29] Botta L, Buttazzi K, Russo V, et al., 2008, Endovascular Repair for Penetrating Atherosclerotic Ulcers of the Descending Thoracic Aorta: Early and Mid-Term Results. Ann Thorac Surg, 85:987992.

[30] Scharrer-Pamler R, Kotsis T, Kapfer X, et al., 2003, Complications after Endovascular Treatment of Thoracic Aortic Aneurysms. J Endovasc Ther, 10:711-718.

[31] Schelzig H, 2004, Endovaskuläre Therapie Des Symptomatischen Aortenulkus. Gefasschirurgie, 201-208.

[32] Amabile P, Grisoli D, Giorgi R, BartoliJM, Piquet P (2008) Incidence and Determinants of Spinal Cord Ischaemia in Stent-Graft Repair of the Thoracic Aorta. Eur J Vasc Endovasc Surg, 35:455461. 